\title{
Study on Ecological Remediation Method of Purification of Rural Polluted Slow-Flow Water
}

\author{
Liqiang XU \\ Pearl River Hydraulic Research Institute of PRWRC \\ Key Laboratory of the Pearl River Estuarine Dynamics and \\ Associated Process Regulation, Ministry of Water \\ Resources \\ Guangzhou 510611, China \\ e-mail: xu_liqiang@163.com
}

\section{Jianghua YU}

School of Environmental Science and Engineering Nanjing University of Information Science and Technology

Nanjing 210044, China

e-mail: yujh@nuist.edu.cn

\author{
Haixia YU \\ Center for Water Resources and Environment \\ Sun Yat-sen University \\ Key Laboratory of Water Cycle and Water Security in \\ Southern China of Guangdong High Education Institute \\ Guangzhou 510275, China \\ e-mail: yuhaixia@mail.sysu.edu.cn
}

\author{
Huan LUO \\ Pearl River Hydraulic Research Institute of PRWRC \\ Key Laboratory of the Pearl River Estuarine Dynamics and \\ Associated Process Regulation, Ministry of Water \\ Resources \\ Guangzhou 510611, China \\ e-mail: gzluohuan@163.com
}

\begin{abstract}
Zhaoxu LI
Pearl River Hydraulic Research Institute of PRWRC

Key Laboratory of the Pearl River Estuarine Dynamics and Associated Process Regulation, Ministry of Water Resources Guangzhou 510611, China e-mail: syslzx@126.com
\end{abstract}

\begin{abstract}
Slow-flow water is the main part of rural water, human activities to the semi-enclosed water caused serious pollution. Water bio-ecological remediation method can increase the ecosystem diversity, self purification capacity and system stability. The technology includes adding microorganisms, constructed wetlands, ecological revetment, biological manipulation, remediation of aquatic vegetation, artificial aeration. The ecological remediation technology practice of moist areas in southern China by pollution slow-flow water including: ecological floating island, anaerobic + artificial wetland, underground integrated equipment + ecological floating island, grit chamber $+\mathrm{AO}+$ artificial wetland + oxidation pond, constructed wetlands + oxidation pond, anaerobic oxidation + oxidation pond, highly efficient and stable pond. The engineering practices show that the ecological remediation method can effectively purify the pollution of slow-flow water.
\end{abstract}

\section{Keywords-slow-flow water; pollute; ecological remediation}

\section{INTRODUCTION}

Water is the most active control factor of ecological system. The increasing ecological crisis further emphasizes the urgency of the construction of water ecological civilization. Water ecological civilization construction requires not only advanced concepts and excellent systemic warrant, but also the need for more scientific and technological support during the specific implementation[1]. Ecological reconstruction could be achieved through two general development ways: one is that try to reconstruct the real past ecosystems, especially which have been destroyed by human beings through changed or abused activities. The other is to reconstruct a degraded ecological system based on the completely destroyed the original ecosystem [2]. River ecological restoration project needs to clear the objective and quantitative ecological restoration goals[3]. Internationally, the European Union Water Framework Directive proposed 5 levels of surface water ecosystem standards with a series of technical guidelines and methods [4-6].

Slow-flow water is the main part of the rural water, various forms of rural area of river and reservoir including reservoir aquaculture, geomantic pond and landscape pond and reticular inland. With the rapid development of rural economy, the improvement of people's living standards and the increasing urbanization, pollutants emissions greatly exceeds the self-purification of the ecological system, aquatic environment of the river and the reservoir all have been impacted. Inland river and reservoir is an interrelated ecological system. The eutrophication and pollution of inland river and reservoir water has been accelerated due to the influence of human activities and the ignored aquatic ecological balance and environmental protection. Accordingly, fish disease events increase, water pollution 
incidents occur frequently. Those changes in aquatic problems seriously affect the production of aquaculture and sustainable development of the reservoir and surrounding residents' health, has become one of the focus issues in the rural areas of the basin.

\section{RESEARCh Status OF SLOW-FLOW WATER POLLUTION AND ECOLOGICAL REMEDIATION}

Rural inland river and reservoir slow-low water contact with the people very close, the rapid development of human activities and the life level generate great pressure to these semi-enclosed waters. Outmoded equipments, over-standards of tail water discharge, the appearance of local untreated discharge, all above result in the various sources, multiple pathways, and complex types of river and reservoir pollution. Great of domestic sewage and industrial waste water are carried into the river and reservoir through sewage mouth. Eutrophication is caused by the excessive input of nutrients which are released from sediment. Surface deposited pollutants are brought into the inland river and the reservoir with rainfall runoff. The decomposed residue of dead fish or animal manure in the river and reservoir will also affect the water quality. A large number of compounds containing phosphorus get into inland river and reservoir caused by nearby residents washing. The accumulation of these pollutants in the river and reservoir result in the serious pollution, eutrophication, distribute odor. And the water ecological system suffers a serious threat. It directly affect the survival of the original biological, even some heavy metal ions affect the human health through food chain.

Water ecological restoration could be achieved through adopting various biological populations and structure which can repair damaged aquatic ecosystem with applying ecological system principle. This process can reconstruct a healthy aquatic ecosystem and repair and strengthen the main function of the aquatic ecosystem, and achieve the overall coordination of the ecological system, self-sustaining, self succession of virtuous cycle. Polluted slow-flow water mainly includes nutrients(nitrogen and phosphorus) and organic matter. The water eutrophication control started earlier in the world, the polluted water has been a better recovery after a long period of "Pollution first, Treatment second" of the control model[7]. China has accumulated a lot of valuable experience in the long-term exploration of water pollution and control [8-10].

Ni Jinren and Liu Yuanyuan [11] divided the water remediation objectives into two categories: water pollution control and ecological restoration goals. They believed that China's ecological restoration will just only target to improve water river water quality, not yet fully realize the goal of ecological restoration [12]. Bio-ecological method is a new sewage treatment method. It is mainly through planting, culture aquatic plants or other methods to removal pollutants in polluted water, so that the water pollution has been effectively improved [13-14]. It's a kind of purification method to achieve harmony between human beings and nature [15-19]. Bio-ecological method has been widely used in practical engineering in the United States, Japan and other developed countries. In many developing countries such as
China, Brazil has also been a rapid development.

The research and application of the bio ecological restoration can be roughly divided into three aspects: One is to apply microbial bioremediation technology as the main body. Biological engineering companies have entered the stage of the application test in America, Japan and China. Especially there are successful examples in the local area. The second is the application of higher plants as the main plant ecological restoration technology. It's suitable for large area, low concentration of pollution sites, it is easy for the public to accept because the plant repair is a natural process. The third is based on the principle of "food chain" biological manipulation techniques, application of tilapia and silver carp and shellfish, such as filter feeding animal stocking and phytoplankton community structure optimization, it play obvious role to control eutrophication and algal blooms in the water.

\section{ECOLOGICAL REMEDiATION METHOdS AND TeChNical Measures of POLLUTEd Water}

Water bio-ecological remediation method to repair polluted water by using the plants or microbial activities through transfer, conversion and degradation of pollutants in the water. The significance of ecological remediation: A, increase the diversity of ecosystem. Including the diversity of ecological environment, species diversity, landscape diversity, functional diversity, etc. $\mathrm{B}$, increase the self purification capacity of ecosystem. For the aquatic ecosystem, increase the settlement of contaminants in water phase, reduce the release of pollutants in sediments, improve water transparency, and inhibit the occurrence of algal blooms. For terrestrial ecosystems, reduce the amount of pollutants into the lake. $\mathrm{C}$, increases the stability of the ecosystem, and enhances the ability of natural water body to resist external interference. Pollution and destruction of the ecosystem are often less stable, more sensitive to changes in the environment, ecological restoration including the restoration of system diversity, it will greatly improve the stability of the ecosystem.

\section{A. Adding Microorganisms}

Adding microorganisms technology is a method by directly putting exogenous degradation bacteria into polluted water, and then use adding microbial to active the original microorganisms. Eliminate the water organic pollution and water eutrophication through their rapid proliferation and strongly suppress harmful microbial growth and activity. It can not only eliminate the black odor of water, but also play a certain role in the purification of sediment. At present, this method is commonly used as centralized biological system (CBS), high efficient composite microbial flora (EM) and immobilized bacteria and other technologies.

\section{B. Constructed Wetlands}

Constructed wetland is a man-made matrix by stone, sand, soil, coal cinder according to a certain proportion, and selected plants of ecological system for sewage treatment. It combines the advantages of natural purification and biological membrane method, and it has been widely 
concerned about the combination of sewage purification, sewage recycling and landscaping. Since 1970s, as a new kind of wastewater treatment technology, the constructed wetland has been widely used in Europe, and has been developed in United States and Canada, and other countries. Large-scale artificial wetland research started from the " seventh Five year plan" period in China, established artificial wetland test base team such as Changping, Tianjin, Beijing, Shenzhen, Wuhan and Chengdu and etc..

\section{Ecological Revetment}

Ecological riparian remediation often applies materials of stone, block stone, square stone, grouting gravel, stone basket, concrete and turf, etc. Stone riparian is the most widely used type due to the relatively low cost, strong water impact resistance. Concrete slope protection in the country is also very common, which is characterized by high strength, aging, stable, but it is of cost high and poor permeability, plants and animals can not be compatible with the ecological environment and the maintenance of the ecological environment of the river. The stone basket can be fixed according to the requirement, the application is flexible, the surface layer can cover the soil, and the vegetation is planted. Grassed revetments in recent years is gradually applied in urban river revetment engineering, assist in rivers and groundwater mutual adjustment, and can alleviate the heavy rain on the river bank erosion, in line with ecological requirements, has broad prospects. Under natural conditions, revetment shape distribution is usually and banded structure parallel to the water's edge, in the ecological dynamics of the system with multiple functions, mainly displays in: channel and the role of corridor, filtration and barrier effect, environmental effects.

\section{Biological Manipulation}

Aiming at the problem of eutrophication- cancer of the water body, aquatic biologists try to make an exploratory research on the point of aquatic populations' structure adjustment, and put forward the eutrophic lake management concept-biological control theory. Biological control is the removal of planktivorous or add fish and animals to reduce the number of plankton feeding fish, zooplankton biomass increased and increased size, mainly Cladocera, so as to improve the zooplankton on phytoplankton feeding efficiency, reduce phytoplankton quantity and improve transparency, improve water quality. Application in practice attend to reduce $50 \%$ 100\% of plankton feeding fish, or high density fish feeding habits of fish to reduce plankton feeding fish. Studies have shown that if the stocked fish species or quantity is not appropriate, may further improve water eutrophication, because the fish affecting the water quality through the digestion and metabolism and excretion of eutrophication. There may also undermine the beneficial aquatic plants, the introduction of parasites, change the original biological communities, may lead to the occurrence of algal bloom.

\section{E. Remediation of Aquatic Vegetation}

Large aquatic plant is the primary producers in aquatic ecosystem. Nutrients absorption of aquatic plant in the water can inhibit algae growth, purify toxic hazardous substances, and can promote microbial degradation of organic matter. The restoration of aquatic vegetation has attracted people's attention, and some valuable experience has been achieved. Restoration and reconstruction of aquatic higher plant communities can effectively purify eutrophic water. By means of environmental dredging and other biological measures, such as physical measures and constructed wetland, it can not only remove the water pollutants, but also create conditions for the restoration of aquatic organisms. Therefore, water ecological restoration includes create suitable basic environment - establish biological pioneer community - the target community development evolution process of the repair, environmental transformation and control is the beginning and foundation of ecological restoration.

\section{F. Artificial Aeration}

Water purification process will be very slow relying on natural aeration. Artificial aeration can also produce the same effect of natural aeration. Water self purification process is always in aerobic condition by using artificial aeration at a appropriate position recharge of oxygen while the water is at anoxic or anaerobic conditions caused by the serious organics pollution. Therefore, the method of artificial aeration can be used to fill the water body with oxygen, to accelerate the process of re oxygenation of the water body, and to improve the activity of aerobic microorganisms in the water body. According to the requirement of improving the aeration water quality requirements (such as the elimination of black odor, improve water quality, ecological restoration) and hydraulic conditions (including water depth, flow velocity, section shape of river, the surrounding environmental conditions), water functional requirements (such as shipping function, landscape function, etc.), characteristics of pollution sources (such as the long-term pollution load, impact of pollution load, etc.), two forms of artificial aeration are generally used which are fixed oxygen filling stations and mobile charging oxygen platform. A common artificial aeration technology includes aeration boat, deep water aeration, hanging chain aerating, oscillating jet aeration, and micro bubble pure oxygen aeration.

\section{Practice Projects}

Southern China humid area typical ecological restoration of polluted slow- flow water includes: ecological floating island, anaerobic + artificial wetland, underground integrated equipment + ecological floating island, grit chamber $+\mathrm{AO}+$ artificial wetland + oxidation pond, constructed wetlands + oxidation pond, anaerobic oxidation + oxidation pond, highly efficient and stable pond(Table I). 
TABle I.. SOUthern China Humid AREa Typical Ecological Restoration of POlluted SLOW- Flow Water

\begin{tabular}{cllc}
\hline $\begin{array}{c}\text { Serial } \\
\text { numbers }\end{array}$ & \multicolumn{1}{c}{ Project name } & \multicolumn{1}{c}{ Ecological restoration technology } & $\begin{array}{c}\text { Scale of } \\
\text { construction (t/d) }\end{array}$ \\
\hline 1 & $\begin{array}{l}\text { Polluted water treatment project for the } \\
\text { village of Tucheng }\end{array}$ & Ecological floating island & 165 \\
2 & $\begin{array}{l}\text { Polluted water treatment project for the } \\
\text { village of Donglintou }\end{array}$ & Anaerobic + artificial wetland & 180 \\
3 & $\begin{array}{l}\text { Polluted water treatment project for the } \\
\text { village of Xianshi }\end{array}$ & $\begin{array}{l}\text { Underground integrated equipment + } \\
\text { ecological floating island } \\
\text { Grit chamber + AO + artificial wetland + } \\
\text { oxidation pond } \\
\text { Constructed wetlands + oxidation pond } \\
\text { community of Yujing }\end{array}$ & 165 \\
6 & $\begin{array}{l}\text { Polluted water treatment project for the } \\
\text { community of Xinlong } \\
\text { Polluted water treatment project for the } \\
\text { community of Gounan } \\
\text { Polluted water treatment project for the } \\
\text { community of Dajiao }\end{array}$ & Anaerobic oxidation + oxidation pond & 180 \\
\hline
\end{tabular}

\section{A. Polluted Water Treatment Project for the Village of Tucheng}

The polluted water treatment for the village of Tucheng uses ecological floating island and biochemical fiber combination of new forms (Fig. 1). Artificial floating island device has a double structure composed of floating frame, filler, plants, floating bed and fixing device. In order to create the different dissolved oxygen area, the lower layer is filled with the new type of ecological fiber filler with good water performance. The mediums simulate aquatic natural form and oxygenation in tubular diameter variability, no clogging, and it is hydrophilic, lipophilic and has good cutting effect on the bubble, oxygen storage function, and strong adsorption capacity. Biofilm adsorbed on the medium within the floating island device system could be constantly updated with the air impulse, which in turn result in high biological activity and high mass transfer efficiency. And the installation is very convenient. Ecological fibers are suspended below the water surface, and the flow velocity is perpendicular to the surface of the water. Plant placement of the substrate using sponge or coconut fiber, nutrients, etc., has a good effect of nitrogen and phosphorus removal through adsorption and sedimentation, and root absorption and other effects. The lower ecological fiber has a good effect on the removal of pollutants by absorb the super large specific surface area and the late biofilm microbial degradation.

\section{B. Polluted Water Treatment Project for the Village of Donglintou}

Rainfall and sewage combined drainage system is applied for the village of Donglintou. An intercepting weir is set for in raw sewage interception. Sewage get into the treatment system usually, the rain water directly into the drainage system when it rains. Considering of the relative high suspended solids concentration in sewage, a grid and a sedimentation pool were designed before the water entering the wetland to avoid wetland clogging. Catchments sink sand pool water drop aeration backward into the cloth trough, the flume cloth of cloth water wetland treatment system.
Remove most of the pollutants after the drains into the ecological ditch in the wetland system, Sewage can be used for agricultural irrigation (Fig. 2).

\section{Polluted Water Treatment Project for the Village of Xianshi}

The drainage system of the village is the way of rain and sewage combined system. Untreated sewage and the rain overflow into the pond during heavy rain period. An efficient artificial ecological system was established based on the existing ecological floating island by using no soil cultivation technology and applying species between symbiotic relationship and make full use of water space niche principle to reduce the pollution load in water. Ecological floating island is a green technology and floating technology combination, not only to reduce the pollution load in water, but also beautify the environment. This project is a non power plant, the pond water surface is always lower than the sewage treatment plant $50 \mathrm{~mm}$ to maintain a constant water head. To prevent the pond water is higher than the drainage port, a set of liquid level control device in the pumping station village was installed (Fig. 3).

\section{Polluted Water Treatment Project for the Community of Yujing}

The water collecting well in the pond and the sewage pipe are designed to collected and discharge the sewage into the domestic sewage treatment system, and the scattered domestic sewage is directly piped into the oxidation pond. Some collected domestic sewage was first collected to the settling basin after separation of large suspended solids by the grid, and then, it was mixed and flow to anaerobic pool. The complicated organic matter which is non biodegradable can be decomposed with anaerobic and facultative microorganism, the sewage overflow into artificial wetlands for further purification, and then get into the ecological floating bed for biological absorption. After that it can be discharged with a satisfied water quality. Scattered sewage can be purified by ecological floating island in biological oxidation pond (Fig. 4). 


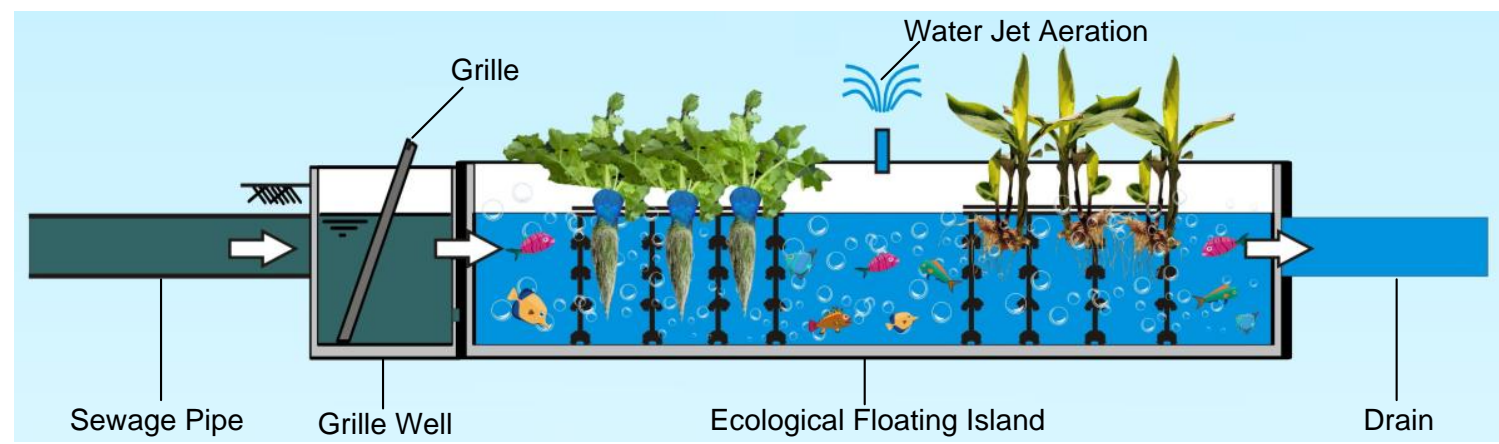

Figure 1. Technological process of polluted water treatment project for the village of Tucheng.

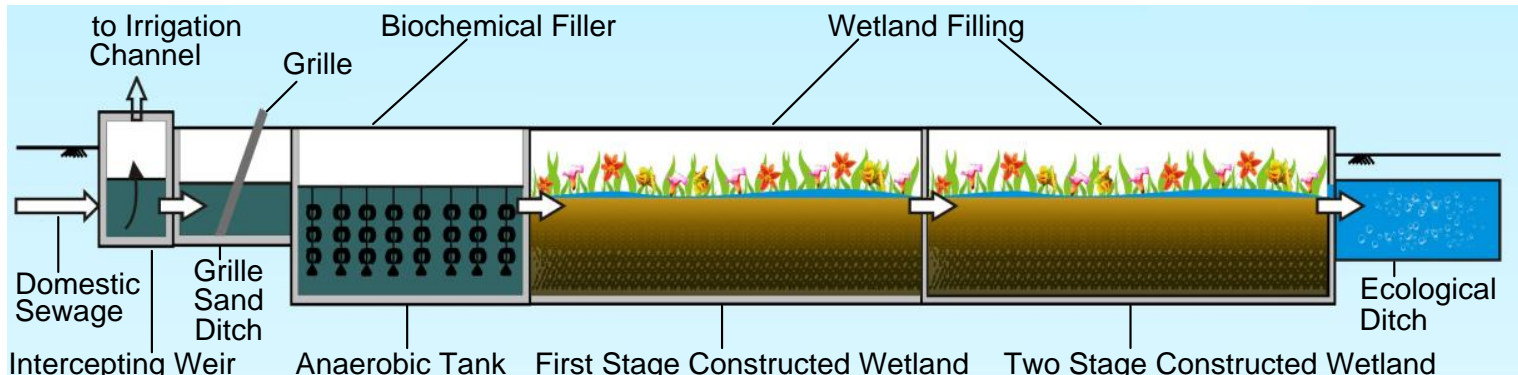

Figure 2. Technological process of polluted water treatment project for the village of Donglintou.

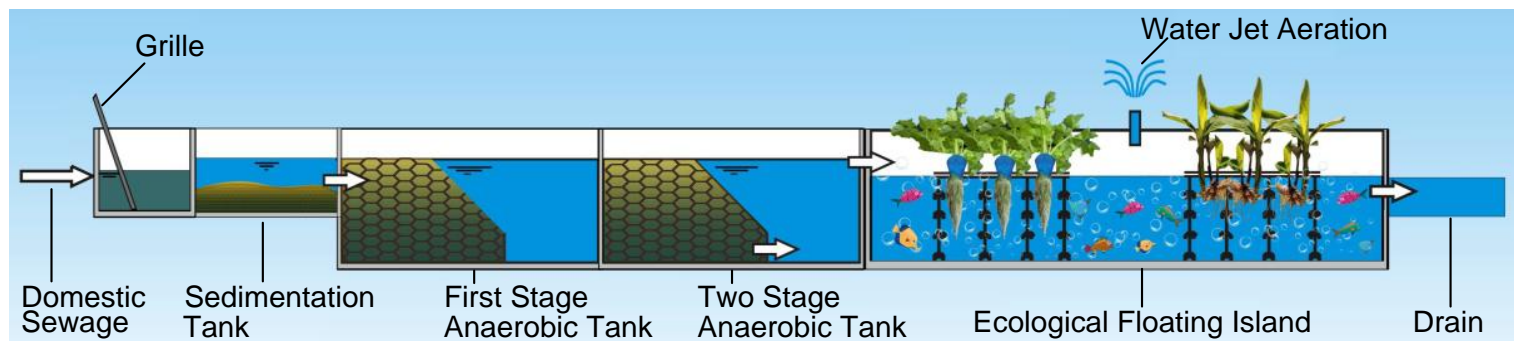

Figure 3. Technological process of polluted water treatment project for the village of Xianshi.

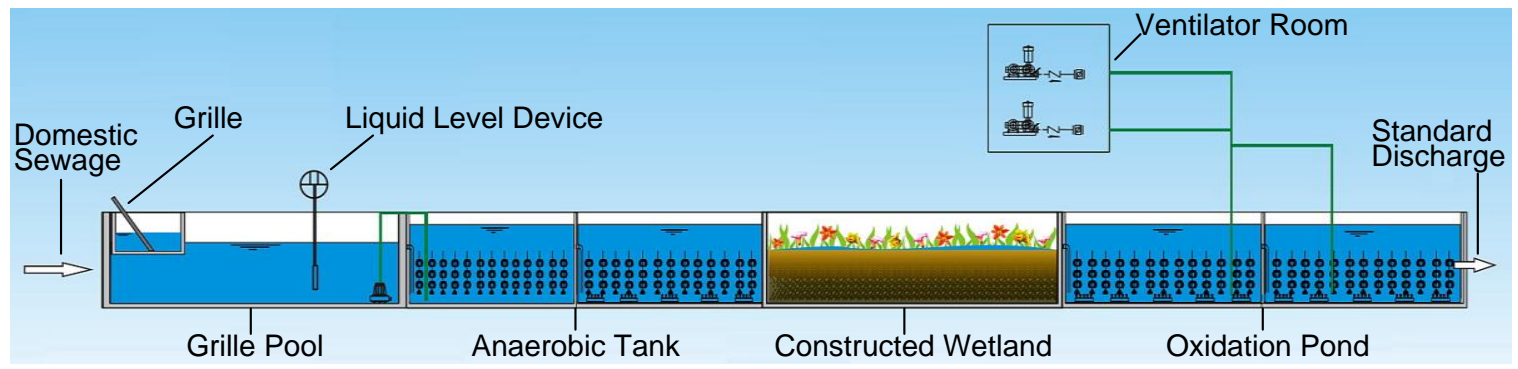

Figure 4. Technological process of polluted water treatment project for the community of Yujing

\section{Polluted Water Treatment Project for the Community of Xinlong}

Domestic sewage get into the artificial wetland through the the sewage ditch. To avoid clogging of wetlands, a grid was designed in front of the wetland to remove part of suspended solids because of the high concentration of SS in the sewage. In the constructed wetland, the water can be purified by adsorption of medium and degradation of aquatic plants. Effluent from the constructed wetland flows into the oxidation pond system for further treatment. An added aeration system in the oxidation pond was used to improve the oxygen for the microbial decomposition. Meanwhile, the plant, microorganisms and medium filtration were applied together to further improve the treatment performance. This combined process is especially effective for the degradation of organic matter and the removal of organic matter. Combined treatment through the above process can keep the water quality good in the pond, at the same time to beautify the village role (Fig. 5). 


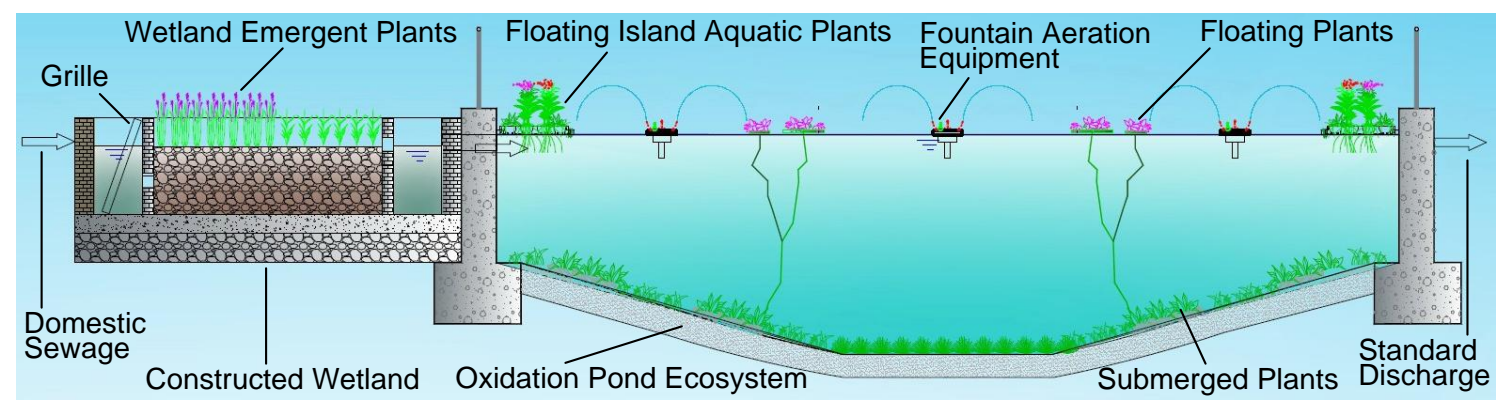

Figure 5. Technological process of polluted water treatment project for the community of Xinlong.
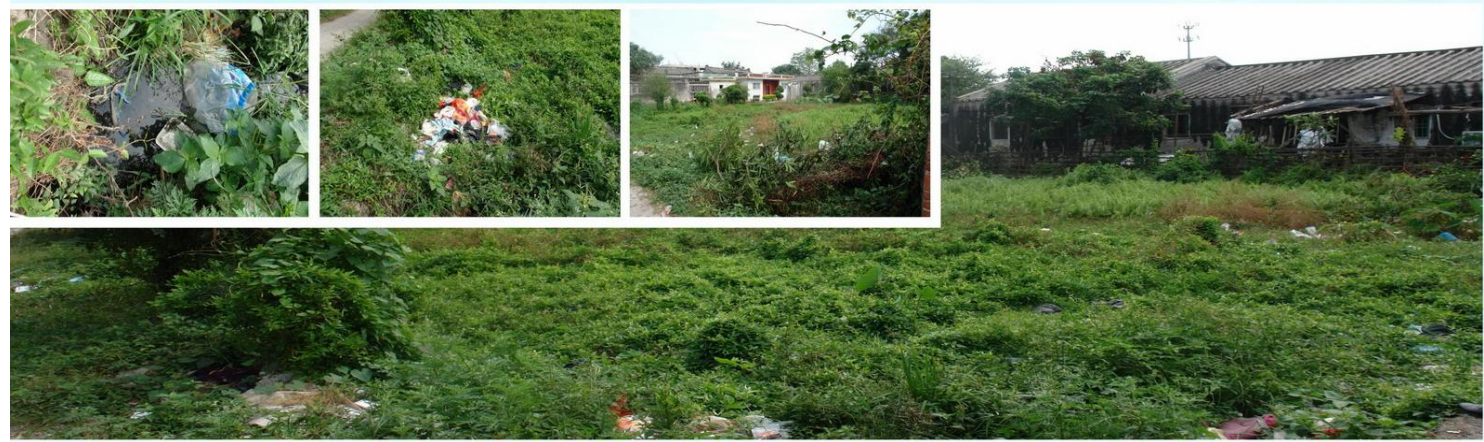

Condition before construction
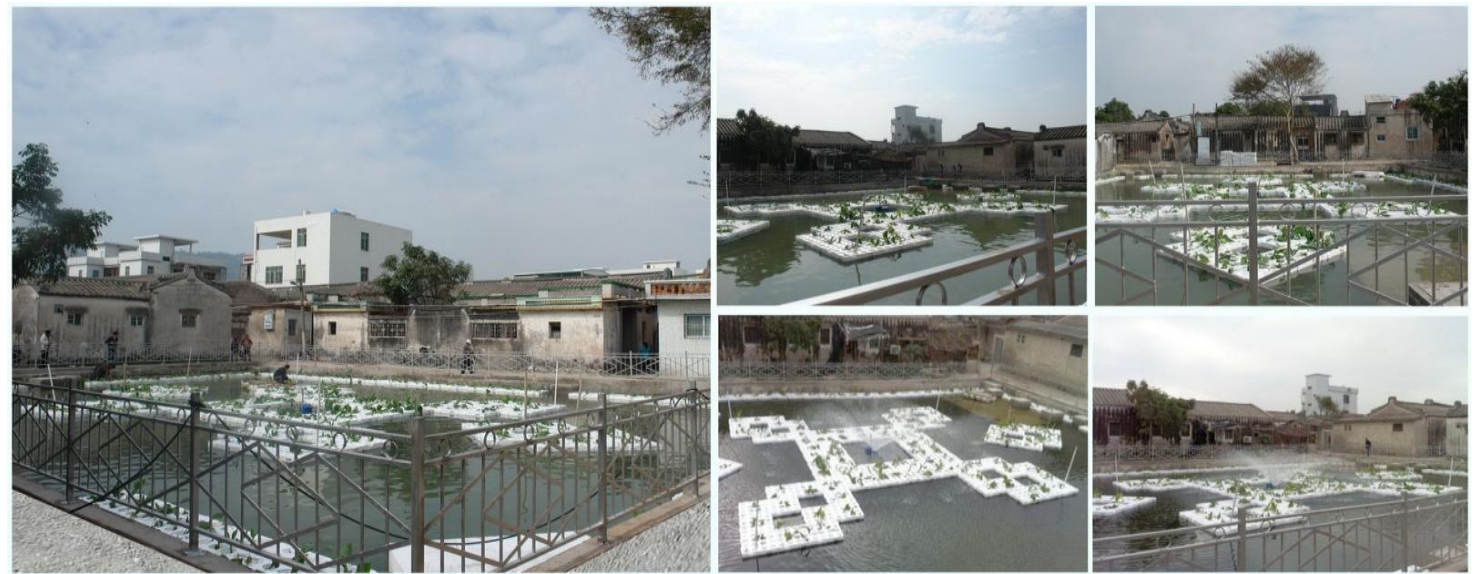

Condition after construction

Figure 6. Condition before and after construction of polluted water treatment project for the community of Gounan.

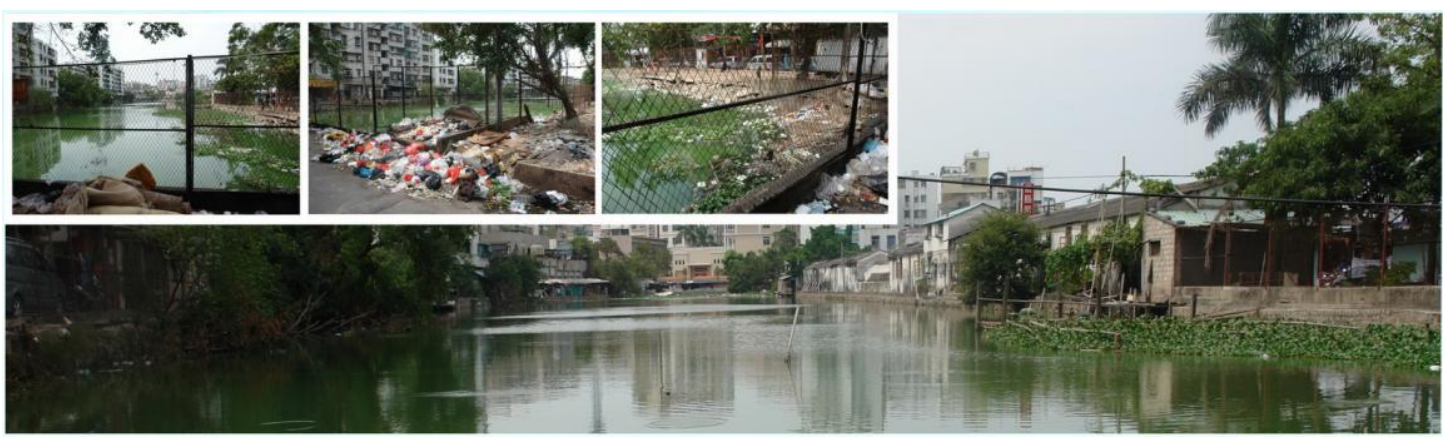

Condition before construction 

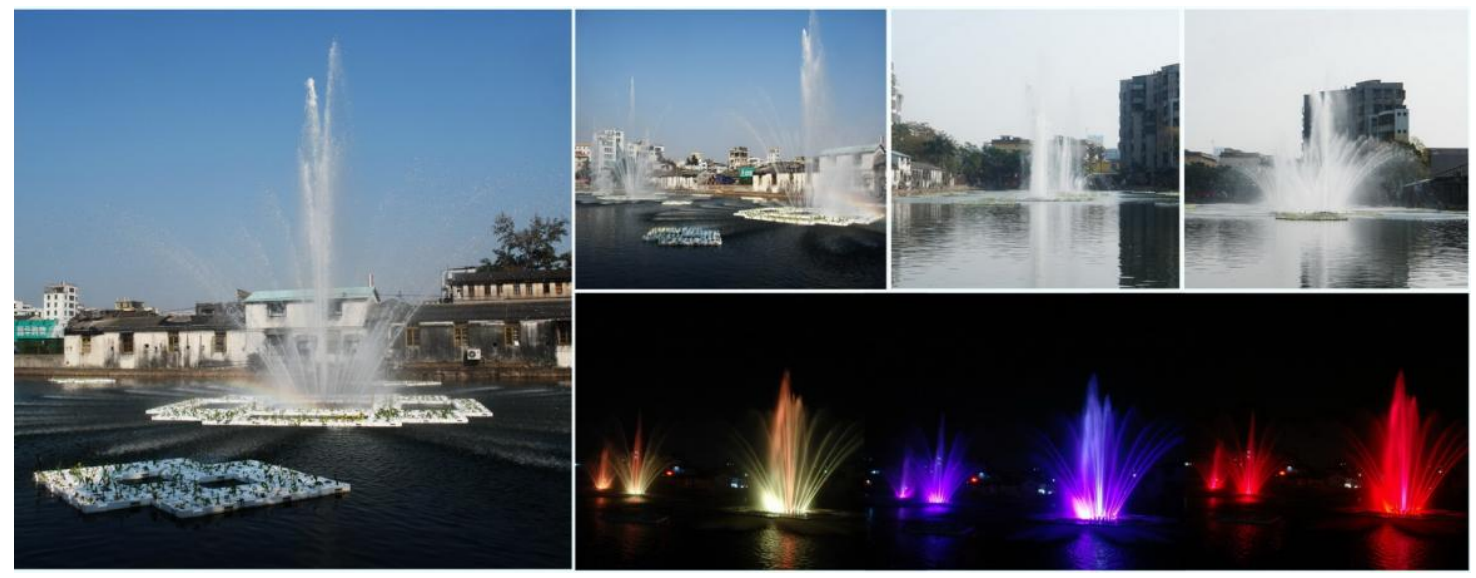

Condition after construction

Figure 7. Condition before and after construction of polluted water treatment project for the community of Dajiao.

\section{E. Polluted Water Treatment Project for the Community of Gounan}

The drainage system in the community of Gounan is a distributed and drainage system, which is used to discharge the sewage in the drainage system. The larger suspended solids are separated by grid before entering the anaerobic pool considering the high concentration of SS in sewage. The sewage is preliminary treated in the anaerobic pool and then get in the aerobic pond for further treatment. Then it discharges into the ecological floating island for biological absorption and further microbial decomposition. Finally, it is discharged into farmland irrigation and drainage ditch for agricultural irrigation (Fig. 6).

\section{F. Polluted Water Treatment Project for the Community of Dajiao}

The efficient stabilization pond is built based on the existing ponds to treat polluted water in Dajiao Project. An ecological floating island system is installed within the stable pond. The sewage can be purified by the microbial decomposition activities with the aerobic and anaerobic conditions, individually, and then it is further treated by ecological floating bed biological absorption (Fig. 7).

\section{CONCLUSION}

As the main part of rural water, human activities and social development bring great pressure to the semi-enclosed slow-flow waters. It's urgent to carry out comprehensive repair for slow-flow water in rural ponds, rivers and reservoirs, and to return a virtuous circle of water ecosystem of the nature. Water bio-ecological remediation method can increase the ecosystem diversity, self purification capacity and system stability. The technology includes adding microorganisms, constructed wetlands, ecological revetment, biological manipulation, remediation of aquatic vegetation, artificial aeration. The ecological remediation technology practice of most areas in southern China includes: ecological floating island, anaerobic + artificial wetland, underground integrated equipment + ecological floating island, grit chamber $+\mathrm{AO}+$ artificial wetland + oxidation pond, constructed wetlands + oxidation pond, anaerobic oxidation + oxidation pond, highly efficient and stable pond. The engineering practices show that the ecological remediation method can effectively purify the pollution of slow-flow water.

\section{ACKNOWLEDGMENTS}

The data of this study was provided by the National Natural Science Foundation of China (Grant No.: 41301627, Grant No.: 41401546). And the preparation of this paper was funded by the Natural Science Foundation of Guangdong Province, China (Grant No.: 2015A030313866) and the Science and Technology Innovative Project of Water Resources of Guangdong Province, China (Grant No.: 2014-12, Grant No.: 2012-15).

\section{REFERENCES}

[1] Zhang Jianyun, Wang Xiaojun. Issues related to building of water ecological civilization. China Water Resources, 2014,7:1-4. In Chinese.

[2] Zhang Xinshi. Ecological reconstruction is the core of the construction of ecological civilization. Science China, 2014,44(3):221-222. In Chinese.

[3] DONG Zhe-ren, ZHANG Ai-jing, ZHANG Jing. Rating system of river ecological conditions and its applications. Journal of Hydraulic Engineering, 2013,44(10): 1233-1238. In Chinese.

[4] Martin Griffiths. Manual of Water Framework Directive. Beijing: China Water Conservancy and Hydropower Press, 2008. In Chinese.

[5] EUROPA. 2003. The EU Water Framework Directive-integrated river basin management for Europe[M/OL]. The European Union Online. URL: http://ec. europa. eu/environment/water/ water-framework/index_en. html

[6] Kallis G, Butler D. The EU Water Framework Directive: measures and directives[J]. Water Policy, 2001,3: 115-124.

[7] SONG Fei-fei, HU Xiao-zhen, JIN Xiang-can, YU Hui. Analysis of lake management strategies of different types of lakes abroad and enlightenments for china. Journal of Environmental Engineering Technology, 2013,3(2):156-162. In Chinese.

[8] ZHAO Jie-chun, BAI Wen-bo, YAMASHITA Ichiji, LI Yu-zhong. Countermeasure for water quality protection and effectiveness in lake district of Japan. Journal of Agricultural Science and Technology, 2011, 13( 6) : 126-134. In Chinese.

[9] Dou Ming, Ma Junxia, Hu Caihong. Analysis of the water 
environmental protection experience of the Great Lake. Meteorological and Environmental Sciences, 2007,30(2): 20-22. In Chinese.

[10] Tu Jianfeng, Jiang Xiaonian, Zheng Feng. Study on the management strategy of lake eutrophication in Europe. Express Water Resources \& Hydropower Information, 2007, 28(14): 8-11. In Chinese.

[11] YANG Jun-peng, WANG Tie-liang, FAN Hao-ming, SU Zi-long. Research progress of river ecological restoration. Research of Soil and Water Conservation, 2012, 19(6): 209-304. In Chinese.

[12] XU Fei, WANG Yonggang, ZHANG Nan, SUN Changhong. Advances in the assessment of river ecological restoration. Ecology and Environmental Sciences, 2014, 23(3): 515-520. In Chinese.

[13] Xu Hai-bo, ZONG Rui-ying. Technology of ecology styles of slope protection for urban river. Construction \& Design for Project, 2005(1):57-59. In Chinese.

[14] Dong Zhenren, Liu Qian, Zeng Xianghui. Bio-Ecological Restoration Technology of polluted water body. Water Resources and
Hydropower Engineering, 2002, 33(2):1-4. In Chinese.

[15] Tyrell W R.Trialing wetlands to treat coal mining wastewater in a lowrainfall, high evaporation environment. Wat Sci Tech, 1997, 35(5): 293-300.

[16] Wiebner A, Kuschk P. Treating a lignite pyrolysis wastewater in a constructed subsurface flow wetland. Wat Res, 1999, 33(5): 1296-1302.

[17] Feng Peiyong, Chen Zhaoping, Jing Yuanxiao. Review on constructed wetland and its the mechanisms of wastewater treatment. Ecologic Science, 2002,21(3): 264-265. In Chinese.

[18] Mitsch WJ, Wise KM. Water quality fate of metals, and predictive model validation of a constructed wetland treating acid mine drainag. Wat Res, 1998.32(6): 1888-1900.

[19] Maria A, Vassilions A. Design Methodology of Free Water Surface Constructed Wetlands. Water Resource Management, 2004, 18:541-565. 